\title{
Cutaneous phaeohyphomycosis in renal transplant recipient
}

\author{
Anvita Anne, Varun Kumar Bandi
}

Department of Nephrology, Dr. Pinnamaneni Siddhartha Institute of Medical Sciences \& Research Foundation, Chinoutpalli, India

Background: Phaeohyphomycosis is a group of mycotic infections caused by dematiaceous fungi (pigmented). It is a rare infection affecting the skin and subcutaneous tissue predominantly, with a wide presentation ranging from subcutaneous nodules to deep abscesses.

Methods: We report a case of phaeohyphomycosis occurring in a renal transplant recipient.

Results: A 48-year-old female with chronic kidney disease secondary to presumed chronic glomerulonephritis underwent live related renal transplant 4 years back, with brother being the donor. She had not received any pre-transplant induction therapy, and was on triple immunosuppression with cyclosporine, mycophenolate mofetil, and prednisolone. She did not have any episodes of acute rejection and had a stable graft function with a serum creatinine of $1.4 \mathrm{mg} / \mathrm{dL}$. She presented with history of multiple blackish swellings over the body for 1 month, present over the neck, forearms, and abdomen, not associated with fever discharge. Excision biopsy of the lesion was done, which revealed presence of phaeohyphomycosis with fungal culture growing Exophiala. She was treated with posaconazole due to multiple lesions which were not excised. She had no recurrence of symptoms and the minor lesions regressed with therapy.

Conclusions: Early suspicion of phaeohyphomycosis in transplant patients is important, as the immunosuppressed state can predispose to systemic spread and severe disease. Treatment consists of simple excision for localized lesions, and posaconazole therapy has showed good results for diffuse disease. Histopathological examination is sufficient for diagnosis when phaeohyphomycosis is suspected. Despite a difficult diagnosis and a rare occurrence, physicians and surgeons should be aware of infection with this emerging fungus, especially in transplant recipients.

Corresponding author: Anvita Anne

E-mail: aanvita1996@gmail.com

(c) The Korean Society for Transplantation

This is an Open Access article distributed under the terms of the Creative Commons Attribution Non-Commercial License (http://creativecommons.org/licenses/by-nc/4.0/) which permits unrestricted non-commercial use, distribution, and reproduction in any medium, provided the original work is properly cited. 